\title{
O CONTRATo SOCIAL E A PRÁtica POLÍtica
}

\section{THE SOCIAL CONTRACT AND POLITICAL PRACTICE}

\begin{abstract}
RESUMO
Sabe-se da influência que o Contrato Social teve, historicamente, na Revolução Francesa (DERÁTHE, 2009 , p. 30); contudo, é possível investigar em qual sentido prático Rousseau gostaria que a obra fosse tomada. O presente trabalho procura se contrapor a uma leitura que pretende tomar o Contrato Social como um modelo de realização política efetiva. Para tanto, percorremos os textos canônicos Rousseau: da teoria à prática (SALINAS, 1976) e O contrato social - entre a escala e o programa (NASCIMENTO, 1988) para pensar as transições que Rousseau faz, na obra, entre o campo abstrato do direito, do dever-ser, e o campo empírico, da prática política efetiva. Acreditamos que, após a análise desses textos, podemos estabelecer de modo mais seguro o vínculo entre a obra de Rousseau e a prática política nos diferentes sentidos que essa obra pode evocar.
\end{abstract}

Palavras-chave: Contrato Social; Prática Política; Direito; Rousseau.

\begin{abstract}
The influence that the Social Contract had, historically, on the French Revolution is known (DERÁTHE, 2009,30 ). However, it is possible to investigate in what practical sense Rousseau would have liked his work to be taken into account. In this sense, the present work seeks to counteract to a reading that intends to take the Social Contract as a model of an effective political achievement. To do so, some canonical texts of Rousseau will be examined: Rousseau: from theory to practice (SALINAS, 1976) and The Social Contract - between the scale and the program (NASCIMENTO, 1988), in order to think of the transitions Rousseau makes in his work between the abstract field of law, duty of being, with the empirical field, of the effective political practice. It is believed that, after analyzing these texts, it will be more safe to establish the link between Rousseau's work and the political practice in the different senses that his work can evoke.
\end{abstract}

Key words: Social Contract; Political Practice; Law; Rousseau.

\footnotetext{
${ }^{1}$ Graduando em Filosofia pela Universidade de Brasília (UnB).

CV Lattes: http://lattes.cnpq.br/0491287669927680.
} 


\section{Introdução}

De acordo com Robert Derathé, o Contrato Social foi considerado na França como o evangelho da revolução de 1789; mas, segundo o mesmo, os estudos dessa relação, "se não falseiam, quase não esclarecem o verdadeiro pensamento do autor" (DERÁTHE, 2009, p. 3031). Talvez, uma das razões para isso seja o fato de os revolucionários franceses terem lido o Contrato Social como uma espécie de "programa político" a ser instaurado na realidade, como nos aponta o professor Milton Meira do Nascimento (1988, p. 128). Mas, se essa leitura não corresponde às pretensões de Rousseau, como ler o Contrato Social, e quais relações ele estabelece com a prática política?

Em outras palavras, essa questão pode ser formulada nos seguintes termos: como se dá, no Contrato Social, a passagem da análise do campo abstrato do dever-ser, o campo dos direitos, para o campo do ser, da história? E como esses dois campos se relacionam entre si e com a atividade humana? Essa questão foi diretamente tratada por Luiz Roberto Salinas Fortes e por Milton Meira do Nascimento.

Nesse viés, o presente texto tratará de recuperar as teses expostas por esses autores no livro Rousseau: da teoria à prática e no artigo $O$ Contrato Social-entre a escala e o programa, para pensar a transição entre esses dois planos e os limites e possibilidades que os mesmos abrem para a prática política. $\mathrm{O}$ texto compreenderá duas partes: na primeira, procuraremos mostrar os limites impostos à leitura dos revolucionários de 1789; na segunda, trataremos de mostrar, de acordo com nossos autores, quais relações com a prática política são abertas por Rousseau no Contrato Social.

O fundamento da limitação que podemos apontar na leitura que os revolucionários fizeram do Contrato é a não distinção entre o que, nessa obra, corresponde ao campo do direito e o que corresponde ao campo da história. De acordo com Salinas, do Livro I até o capítulo VI do Livro II do Contrato teríamos em Rousseau considerações sobre o campo do dever-ser. Essas considerações, que procuram determinar a natureza do corpo político, têm de proceder necessariamente pela abstração dos elementos empíricos, das paixões e, por conseguinte, da história.

A enumeração dos elementos jurídicos necessários a uma verdadeira associação política não são, todavia, suficientes para a instauração da ordem social. Essa insuficiência já anuncia, como veremos mais à frente com o artigo de Milton Meira do Nascimento, que o campo do dever-ser não pode estar em harmonia com a realidade 
factual empírica (NASCIMENTO, 1988, p. 123), isto é, eles não possuem uma estrutura análoga. Tomar esses dois campos como dotados de uma mesma estrutura é a condição que permite que os revolucionários os confundam (NASCIMENTO, 1988, p. 129).

Nesse sentido, a exposição dos limites da leitura que os revolucionários franceses - e, depois deles, muitos outros - fizeram do Contrato Social pode ser realizada mostrando como, para a constituição do campo do direito, impõem-se limites necessários à história, e como, para se pensar a prática política no campo da história, o estabelecimento da esfera dos direitos é insuficiente.

\section{Direito: os limites da história}

No início do Contrato Social, após expor a questão diretiva do livro, Rousseau afirma pretender unir em sua investigação justiça e utilidade (ROUSSEAU, 1978, p. 21). A enunciação desses dois elementos já permite entrever os dois campos que serão articulados nessa obra: o campo do direito - representado na ideia de justiça - e o campo da prática - representado na ideia de utilidade.

A partir de uma exigência histórica - aquela na qual a solidão da vida primitiva não é mais capaz de fornecer os meios necessários para a conservação de cada indivíduo -, as relações humanas se fazem necessárias. Essa exigência do mundo prático traz consigo a questão de como se devem relacionar politicamente os homens.

Salinas, analisando o Contrato Social e seguindo a lógica interna do texto de Rousseau, desdobra essa questão em outras duas. A primeira pode ser formulada como "o que pode legitimar a mútua dependência entre os homens?”. Essa questão, diz ele, permite pensar as "condições de possibilidade de uma sociedade justa", assim como "determinar a essência do corpo político". Tal questão - veremos por quê - só pode ser respondida se recorrermos ao campo do direito. Por outro lado, a segunda questão diz respeito ao campo da história, e nela podem ser pensadas “as formas concretas que o corpo político pode assumir" (SALINAS, 1976, p. 74).

Trataremos aqui de mostrar, seguindo o texto de Salinas, quais limites são impostos à história para a determinação de um ideal de justiça ou da essência do corpo político, ou seja, a razão pela qual o recurso à história é insuficiente para a determinação de um ideal político. 
Para Salinas, a história é incapaz de nos fornecer uma imagem da natureza essencial do corpo político, e esse é seu limite. Para pensar a questão do que pode legitimar a ordem política, Salinas se pergunta pela forma como os homens devem se relacionar no interior dessa ordem. Essa pergunta, diz ele, corresponde a investigar um modelo de ordenação das relações que seja universalmente válido. Contudo, como a história pertence ao reino do artifício, ela é incapaz de nos fornecer esse modelo. Para além dela, afirma o autor, é necessário investigar a natureza mesma do corpo político. A identificação dessa natureza depende da pergunta do que pode legitimar a ordem social. Já que nenhuma sociedade é formada naturalmente, devido à liberdade natural do homem, a resposta a essa pergunta só pode se dar nas convenções, pela investigação do "fundamento da própria associação" entre os homens (SALINAS, 1976, p. 75-77).

Como explicar o fundamento da associação entre os homens, e como entender melhor os limites que são postos à história na determinação desse fundamento?

Segundo o referido autor, o elemento necessário para explicar o fundamento da associação é o ato produtor da ordem política, na medida em que tanto a ordem natural quanto a ordem convencional são "da ordem do produto", e o que diferencia ambas é a diferença do "agente produtor". Assim, a questão melhor formulada deve ser a de determinar o ato que produz a associação entre os homens. Essa determinação não pode ser feita recorrendo à história, na medida em que não interessa localizar, num lastro de tempo, o momento determinado em que se deu essa associação.

De acordo com Salinas, a figura do ato contratual acontece "num instante, fora do tempo". A questão que interessa, na verdade, é a de saber "qual o ato que constitui necessariamente o corpo político" (SALINAS, 1976, p. 77-78). O ato que institui o corpo político necessariamente não pode aparecer na história porque, sendo o ato que institui o corpo político um ato de vontade e, segundo o autor, sendo a paixão o que particulariza e diferencia os homens na história, a abstração dos elementos concretos - para que identifiquemos o ato pelo qual a associação vem a existir necessariamente - deve proceder pela abstração das paixões da vontade, permitindo pensar uma vontade puramente racional, que se oriente segundo o "verdadeiro interesse do homem" (SALINAS, 1976, p. 78).

Igualmente, para o autor, o homem que é orientado por essa razão escolhe sempre "a melhor associação possível”. Assim, a história é limitada em relação à sua possibilidade de nos fornecer a natureza ou essência do corpo político, porque nela os homens, movidos pelas paixões, não são guiados por um interesse puramente racional.

Em conformidade, para ele, o estabelecimento da forma de associação legítima depende da conciliação das exigências contraditórias do interesse (unir as 
forças para sobreviver) e da justiça (não abrir mão da própria liberdade sem degradar-se). Isso só é possível com a predominância da vontade geral, na medida em que a vontade geral, sendo a "vontade de cada membro da associação, enquanto dirigida ao interesse geral da comunidade", permite que cada membro da associação obedeça apenas a si mesmo. A condição necessária, mas não suficiente, dessa supremacia é a "alienação total de cada associado com todos os direitos a toda a comunidade" (SALINAS, 1976, p. 80).

Salinas percebe que a questão da legitimidade da dependência entre os homens é a mesma questão da essência do povo. Essas duas instâncias, definição de um ideal e definição da essência do fenômeno político, confundem-se na medida em que a mútua dependência entre os homens é legítima quando se trata de um povo propriamente - que, diferentemente do agregado, tem como sua forma de organização originária uma relação jurídica (SALINAS, 1976, p. 79). Isto é, o povo passa a existir quando há uma passagem, na forma de relação entre os homens, da força para a lei. Assim, diz Salinas, "a determinação da origem das sociedades se confunde, de fato, com a determinação da origem das leis" (SALINAS, 1976, p. 79-80).

Nesse sentido, de acordo com o autor, para determinarmos a essência do corpo político é necessário determinar sua pretensão, que é a pretensão de legalidade. Todavia, embora o problema da legitimidade da dependência se confunda com o problema da essência da ordem legal, é necessário saber em quais condições o legal é legitimo (SALINAS, 1976, p. 80).

O legal é legítimo quando a legalidade realiza sua pretensão essencial, ou seja, a conciliação entre interesse e justiça. Quando o legal é estabelecido tendo em vista apenas a utilidade, como é o caso do segundo Discurso, de acordo com Salinas, não podemos dizer que se trata de uma união perfeita. Dessa forma, Salinas mostra como o princípio diretor da investigação de Rousseau no Contrato é o princípio do melhor, pois se dá na suposição (ideal) de uma perfeita realização das pretensões da essência da associação.

$\mathrm{O}$ ato do contrato tem como função, de acordo com Salinas, radicalizar o conceito de convenção, que tem como forma essencial o consentimento. Esse consentimento, afirma Salinas, constitui o fundamento de qualquer sociedade. Sem ele não há ordem legal, e sem ordem legal não há povo. Contudo, o nível de expressão e consciência do consentimento pode variar, o que nos fornece diferentes imagens, que variam da melhor convenção à pior.

\section{História: os limites do direito}


Nos capítulos VI e VII do Livro II do Contrato, Salinas identifica uma mudança de plano no ponto de vista da investigação de Rousseau. Se antes sua tarefa foi a de determinar um ideal político, trata-se agora de pensar as condições históricas de sua realização (SALINAS, 1976, p. 93). Essa tarefa tem como figura-chave o Legislador. O Legislador, segundo o referido autor, é o responsável pela existência efetiva do corpo político, que antes só existia teoricamente, mas que só vem a cabo com a ação dessa personagem pela tarefa da instituição de elementos que proporcionem a conservação do corpo político, colocando de fato os indivíduos sob direção da vontade geral. Essa conservação, portanto, é a condição da realização empírica do corpo político (SALINAS, 1976, p. 93).

O vão entre a determinação da essência da ordem política e sua realização mostra, diz Salinas, que entre a enunciação da cláusula do contrato - a alienação geral - e o seu cumprimento há um hiato. Tal hiato é estabelecido por três exigências históricas que anunciam, por sua vez, os limites do campo do direito no que diz respeito à instituição do corpo político. As três exigências correspondem à superação de uma limitação ética, à superação de uma limitação epistemológica e à necessidade da instituição de uma "ordem afetiva", para usar as palavras de Salinas, a fim de que a ordem política venha a ser historicamente. Vejamos mais de perto no que consistem essas exigências.

Salinas expõe esses limites justificando, com Rousseau, a necessidade da política (SALINAS, 1976, p. 94). O autor procura evidenciar essa necessidade a partir de duas consequências que ele tira da natureza artificial do corpo político.

Em primeiro lugar, a política é necessária porque, se o os homens pudessem harmonizar seus interesses sem o auxílio dela, as instituições políticas seriam supérfluas. Efetivamente, Salinas procura mostrar como o momento da necessidade do pacto corresponde a uma mudança nos indivíduos, que faz com que o amor-próprio ganhe prevalência sobre o amor de si. A distância mesma entre a promessa e o cumprimento do pacto "corresponde", diz ele, "aos graus de distanciamento da condição primitiva". É esse distanciamento, por sua vez, que impede a harmonização "espontânea" dos interesses e faz necessária uma harmonização artificial. Nesse sentido, para Salinas a mediação da política, a harmonização artificial, viria para garantir o efetivo cumprimento - pelo estabelecimento de sanções e pela garantia de reciprocidade no estabelecimento das leis - das obrigações pelos particulares, que, sem isso, tentariam "gozar os direitos de cidadãos sem preencher os deveres de súdito". Isso é, pois, o que se anunciou como limite ético.

Em segundo lugar, porque o Estado é um ente artificial e convencional, o interesse geral não é sensível à razão; não é, diz Salinas, "transparente para a 
máquina artificial o que deve ser feito para sua conservação”. Esse é o limite epistemológico. A superação de tal limite acontece pela definição do bem público concretamente por um sistema de leis (SALINAS, 1976, p. 96). Esses dois limites estariam expressos, usando as palavras de Salinas, na "insuficiência de nossa razão e da nossa sensibilidade como na corrupção da nossa vontade”. Suas respectivas superações (ou pelo menos a tentativa de tais) aconteceriam pelo estabelecimento de um sistema de leis, que seria a "expressão da vontade geral", e de um governo, de acordo com Salinas, "órgão capaz de garantir a execução da vontade geral” (SALINAS, 1976, p. 96-97). ${ }^{2}$

Contudo, Salinas afirma que a definição de um sistema legislativo e o estabelecimento de um governo "não esgotam a tarefa de conservação do corpo político" (SALINAS, 1976, p. 103). É necessário ainda, para o autor, o estabelecimento de uma "verdadeira união", que só pode acontecer com a formação de cidadãos que tenham o interesse guiado pelo amor à pátria.

Como essa transformação não acontece naturalmente - já que, segundo o próprio autor, o reconhecimento da necessidade de uma associação pelos homens não significa um abandono de seu "egoísmo" (SALINAS, 1976, p. 103) -, é necessário que o Legislador seja capaz de transformar a natureza humana, alterando o princípio de seu querer, que está baseado, nesse período, no amor-próprio, parar fazer os homens passarem da condição de unidades absolutas para a condição de partes de um todo (SALINAS, 1976, p. 104). O autor procura mostrar que a formação de homens com "amor à ordem" não pode acontecer de forma espontânea, como poderia parecer, de acordo com ele, a partir da leitura da "Profissão de Fé" (segundo a qual a consciência levaria os homens a amarem o bem desde que eles o conhecessem), já que o amorpróprio abafa, nessa etapa, a voz da consciência.

Assim, não é suficiente que o Legislador revele aos homens o "bem que devem amar", porquanto sua vontade não é reta. É necessário alterar seu querer, "agir sobre a vontade dos homens" para "retificar a vontade dos particulares", pois o que caracteriza o povo no momento da associação, de acordo com Salinas, é que "o público não passa de uma mera abstração, constituído, na realidade, por particulares entre os quais inexiste uma verdadeira união" (SALINAS, 1976, p. 106).

\footnotetext{
${ }^{2}$ De modo mais geral, esses dois limites - assim como a figura do Legislador - podem ser explicados pela concepção da razão como "resultado tardio da história". É fundamentalmente essa condição que permite pensar diferenças entre as razões dos homens e justificar, de acordo com Salinas, uma espécie de "paternalismo" que atenua o "democratismo radical" de Rousseau por uma estrutura de relação pedagógica (cf. SALINAS, F. O Discurso do Legislador. In: Rousseau: da teoria à prática, 1976, p. 97-103).
} 


\section{O Sentido da prática política no Contrato}

Pensar o sentido da prática política em Rousseau é pensar também, como havíamos adiantado, a interação entre o campo dos direitos e o campo da história.

Salinas, ao longo de seu livro, anuncia diferentes possibilidades de ação, que podem ser políticas ou não, no ou a partir do Contrato Social. Essas possibilidades variam de acordo com as circunstâncias e condições que, por sua vez, abrem ocasiões adequadas para determinados tipos de interferência na ordem política. Assim, de acordo com Salinas, a ação do Legislador, se localizada no interior do quadro temporal pintado no segundo Discurso, só pode acontecer com eficiência no período de "maturidade do povo", isto é, naquele lastro de tempo entre o estabelecimento da propriedade e a "corrupção dos costumes" do povo devido ao "triunfo do amor-próprio" (SALINAS, 1976, p. 108-125).

De acordo com Salinas, a ação possível após a corrupção dos costumes do povo não tem mais o povo como conjunto por objeto, passando a se concentrar nos indivíduos. É o momento de relevância da ação pedagógica. Entre esses dois extremos o autor nos apresenta ainda outras duas formas de ação intermediária: temos a que ele chama de "Legislador conselheiro", que seria a função que Rousseau toma ao fazer suas considerações sobre o governo da Polônia e elaborar um projeto de constituição para Córsega; e temos também a do escritor político, que se dirige, por sua vez, ao povo corrompido, e não mais aos governantes (SALINAS, 1976, p. $123)$.

Uma outra relação que o Contrato estabelece com a prática política é anunciada por Salinas, embora não seja desenvolvida, no início de suas considerações sobre o Contrato Social. Devido à sua inserção no Emílio, Salinas percebe que há uma utilidade na especulação política. A exposição da forma como se dá essa utilidade foi feita pelo professor Milton Meira do Nascimento no artigo $O$ Contrato Social - entre a escala e o programa.

Nascimento, nesse artigo, procura explicar um trecho do Emílio de Rousseau no qual o filósofo expõe as regras para a observação política fazendo referência à necessidade do estabelecimento de uma "escala", pela definição dos direitos políticos, para a tomada de "medidas", ou seja, o estabelecimento de leis empíricas, a fim de desconstruir uma leitura que tenta interpretar o Contrato Social como uma espécie de programa político a ser realizado. 
Ao mostrar como essa observação expressa de maneira acertada as intenções de Rousseau ao escrever o Contrato, Nascimento chama a atenção para a própria advertência de Rousseau, na qual o filósofo aponta veementemente para a diferença entre o estabelecimento dos princípios do direito político e o estabelecimento dos princípios do direito positivo. Nascimento procura dar conta dessa distinção analisando duas perguntas, formuladas pelo próprio Rousseau, em relação ao "esclarecimento dessas matérias": "que importa e que fazer?" (NASCIMENTO, 1988, p. 119).

A resposta à questão “que importa?" é a condição de resposta da questão "que fazer?", diz Nascimento. Essa primeira pergunta só pode ser respondida no campo do direito, já que é pela abstração das diferenças empíricas entre os povos e pela identificação de sua essência comum que é possível estabelecer parâmetros para julgar os fatos, que é possível tratar equitativamente as matérias de governo. Nesse sentido, afirma Nascimento, "todo o Contrato Social não passará de uma grande escala, na qual estarão todos os elementos constitutivos das relações de poder, desde o grau máximo da servidão até o grau máximo da liberdade política ou civil" (NASCIMENTO, 1988, p. 120).

Sendo assim, o autor nos mostra como a análise do direito positivo dos povos é insuficiente para fazer tal julgamento e, advertindo-nos a não fazer a frequente confusão entre o que "deve ser" e o "plano de ação", mostra-nos também que do ponto de vista da prática a pergunta mais adequada diz respeito ao campo das possibilidades, “o que posso fazer?”.

Nascimento levanta duas razões que justificam essa posição. Em primeiro lugar, o autor nos mostra que Rousseau, nos textos em que trata de medidas políticas concretas, usa os princípios expostos no Contrato como um "sistema de medidas", em vez de procurar realizar esses princípios tais como são expressos. Em segundo lugar, além da referência ao sistema de medidas, nesses textos vemos outro elemento fundamental estabelecer critério para a definição do programa de ação: é o conhecimento das circunstâncias e condições particulares dos povos que permite não apenas fazer o possível, mas também aquilo que é mais conveniente. $\mathrm{O}$ conhecimento dessas circunstâncias poderia ser resumido, segundo Nascimento, pelo conhecimento dos usos, costumes e opinião de cada povo (NASCIMENTO, 1988, p. 119-122).

De acordo com Nascimento, nessa análise, estamos diante de uma dupla possibilidade de ação. O que se coloca aqui são tanto as condições de julgamento dos corpos políticos como de definição de um programa de ação (NASCIMENTO, 1988, p. 122).

Se, por um lado, o campo dos fatos não permite por ele mesmo a definição de critérios que nos deem parâmetros para julgar as condições concretas, por outro lado, a definição do campo dos direitos por si só não é suficiente - embora ela nos 
forneça a escala - nem para o julgamento de uma determinada ordem política, nem para a definição de um plano de ação. Essa última tem de ser auxiliada pelo conhecimento das condições concretas e dos aspectos diferenciais de cada ordem política.

Desse modo, a diferenciação desses planos, diz-nos Nascimento, longe de constituir uma contradição entre direito e fato, expressa dois momentos necessários e complementares para essas duas ações possíveis (NASCIMENTO, 1988, p. 122-123).

\section{Conclusão}

Nosso objetivo era o de pensar, a partir das contribuições de Salinas e Nascimento, as relações que o Contrato Social de Rousseau estabelece com a prática política. Recusamos de início uma leitura que transportava de forma imediata as formas de organização expostas nesse livro para o mundo prático, e vimos que a relação entre essas esferas é mais complexa. De fato, nossos autores nos evidenciaram determinados critérios que devem ser levados em conta para pensar a relação entre teoria e prática em Rousseau.

Salinas, após evidenciar a diferença estrutural entre direito e fato, separa os tempos oportunos para ação. Há diferentes estágios na história dos corpos políticos, e cada um deles exige uma espécie de ação adequada. Algo de semelhante Rousseau faz no Emílio quando diferencia as atividades pedagógicas segundo as fases da infância. Trata-se de ser coerente, e a coerência exige a consideração das circunstâncias. Além disso, devemos levar em conta, como nos mostra Nascimento, nossos objetivos. Há diferença entre “querer conhecer" e "procurar fazer", entre julgamento e plano de ação.

Em outras palavras, usar o Contrato tendo em vista uma dimensão pedagógica e usá-lo tendo em vista uma utilidade prática para um determinado povo são coisas diferentes. E, nesses dois casos, as definições abstratas do direito e as observações concretas da história exercem funções complementares.

É interessante observar como esses critérios aparecem quando Rousseau coloca o problema político para os poloneses em suas Considerações sobre o governo da Polônia: diante de um estado de anarquia (circunstância), é preciso escolher o mais desejável: a liberdade ou a tranquilidade (objetivo), já que, naquele caso, a busca simultânea desses dois seria improvável (ROUSSEAU, 1982, 24-25). Soma-se a isso, como nos mostrou 
Nascimento, o fato de os princípios do Contrato Social servirem de base para a determinação de ações necessárias à resolução do problema polonês.

Vê-se, portanto, que as considerações jurídicas do Contrato Social não são suficientes para a determinação de uma ação prática, razão que nos impede de definir uma proposta de intervenção na realidade de antemão. Além disso, a relação da teoria com a prática em Rousseau, como bem mostrou Salinas, é uma relação de subordinação (SALINAS, 1976, p. 7173): a transposição da teoria para a prática precisa considerar os objetivos e as circunstâncias. 
Referências

DERATHÉ, Robert. Rousseau e a ciência política de seu tempo [1950]. Tradução de Natalia Maruyama. São Paulo: Barcarolla, 2009.

NASCIMENTO, Milton Meira do. O Contrato Social - entre a escala e o programa. Discurso, São Paulo, 1988, n. 17, p. 119-129.

ROUSSEAU, Jean-Jacques. Considerações sobre o governo da Polônia e sua reforma projetada. Tradução de Luiz Roberto Salinas Fortes. São Paulo: Editora Brasiliense, 1982. . Do Contrato Social. São Paulo: Editora Abril, 1978. _. Emílio ou Da educação. São Paulo: Martins Fontes, 1999.

SALINAS, Luiz Roberto Fortes. Rousseau: da teoria à prática. São Paulo: Editora Ática, 1976. 